\title{
Numerical Simulation Analysis of Stress Distribution in Composite Foundation Reinforced by Rigid Pile with Thick Cushion
}

\author{
Chunhui $\mathrm{Su}^{1}$, Feng Cheng ${ }^{1}$, Aijun Chen ${ }^{1 *}$ \\ ${ }^{1}$ School of Architecture and Transportation Engineering, university of electronic technology, Guilin, Guangxi 541004, China
}

\begin{abstract}
The method of mathematical simulation was adopted to get the stress distribution of composite foundation with thick cushion, rigid foundation and rigid piles. In this paper, 21 models were calculated and get the stress distribution of the pile and the soil around piles in the models with different pile lengths $(9 \mathrm{~m}$, $12 \mathrm{~m}, 15 \mathrm{~m}, 18 \mathrm{~m}, 21 \mathrm{~m})$ and different pile spaces $(3 \mathrm{~d}, 4 \mathrm{~d}, 5 \mathrm{~d}, 6 \mathrm{~d}$ ( $\mathrm{d}$ is diameter)). The result turns out that the position where the minimum stress of soil around piles appear is 3 meters from the pile tip when the space is less than or equal to $4 \mathrm{~d}$, then the stress increases with increasing depth to the maximum at the position where is 3 meters under the pile tip, then the stress starts to decrease with the increasing depth till 0 . The law on the change of additional stress of soil is the same as the natural ground without the processing when the space is greater than or equal to $5 \mathrm{~d}$. The axial stress of piles first increases with the depth and then decreases, and the position where maximum stress appears is $\mathrm{L} / 3 \sim \mathrm{L} / 4$ under the pile top. The total influence depth of additional load increases and the influence depth under the pile tip of additional load decreases with increasing pile length, it decreases with increasing pile space.
\end{abstract}

\section{Introduction}

With the wide range of applications of the rigid pile composite foundation in railway and highway, more and more experts and scholars have studied the reinforcement mechanism and stress distribution characteristics of pile-soil and achieve some results. Wang Bing etc. ${ }^{[1]}$ have analyzed the stress and the carrying load ratio between pile and soil by static load test and obtained the result that the load acting on the pile is smaller because of thicker cushion; Chi Yuejun etc. ${ }^{[2,3]}$ have calculated stress ratio and load ratio between pile and soil when the pile extends into relatively hard soil layer, and found that they increased with increasing pile length and pile space; Xue Xinhua etc. ${ }^{[4]}$ underpinned a viewpoint that vertical bearing capacity of piles increase when the pile length increases, pile space and cushion thickness decreases, reasonable cushion thickness is $20 \mathrm{~cm} \sim 30 \mathrm{~cm}$. Zhu Xiaojun etc. ${ }^{[4,5,6]}$ have put forward the stress ratio of pile-soil; $\mathrm{Li} \mathrm{Li}$ etc. ${ }^{[7]}$ have studied stress distribution of pile in the composite foundation with cushion thickness of $0 \sim 15 \mathrm{~cm}$, and obtained the result that neutral point is $0.3 \mathrm{~L}$ under the pile top, that the thickness of cushion has little effect on neutral point; Zheng Gang etc. ${ }^{[8]}$ thought that cushion obstructs exerting bearing capacity of pile; Yang Jiande etc. ${ }^{[9,10]}$ thought that pile space is too small to bringing the bearing capacity of the soil; Sun Xunhai etc. ${ }^{[1]}$ have analyzed influencing factors of pile-soil stress ratio. But, these results mainly focus on the cushion thickness in the range of $15 \mathrm{~cm} \sim 60 \mathrm{~cm}$ in the composite foundation. In this paper, the stress distribution characteristics of pile and soil under the thicker cushion is calculated and analyzed.

\section{Numerical Simulation Calculation Model and Basic Assumptions}

\subsection{Model Design and Physical Mechanics Parameters}

Numerical simulation analysis of the model is shown in Table 1. Foundation model size is $80 \mathrm{~m} \times 60 \mathrm{~m} \times 45 \mathrm{~m}$. The diameter of the model pile is $0.8 \mathrm{~m}$, the cushion thickness is $2 \mathrm{~m}$. The elastic modulus of the pile is $68.9 \mathrm{GPa}$ and the weight is $27 \mathrm{kN} / \mathrm{m}^{3}$. The physical and mechanical parameters of soil are shown in Table 2. Figure 1 shows the model and meshing. 
Table 1. Numerical simulation model

\begin{tabular}{cccccc}
\hline Number & $\begin{array}{c}\text { Pile length } \\
(\mathrm{m})\end{array}$ & Pile space & Number & $\begin{array}{c}\text { Pile length } \\
(\mathrm{m})\end{array}$ & Pile space \\
\hline No.1 & - & - & - & - & - \\
No.2 & 9 & & No.12 & 9 & \\
No.3 & 12 & & No.13 & 12 & $4 d$ \\
No.4 & 15 & $6 d$ & No.14 & 15 & \\
No.5 & 18 & & No.15 & 18 & \\
No.6 & 21 & & No.16 & 21 & \\
No.7 & 9 & & No.17 & 9 & \\
No.8 & 12 & $5 d$ & No.18 & 12 & \\
No.9 & 15 & & No.19 & 15 & \\
No.10 & 18 & & No.20 & 18 & \\
No.11 & 21 & & No.21 & 21 & \\
\hline
\end{tabular}

Table 2. Physical and mechanical parameters

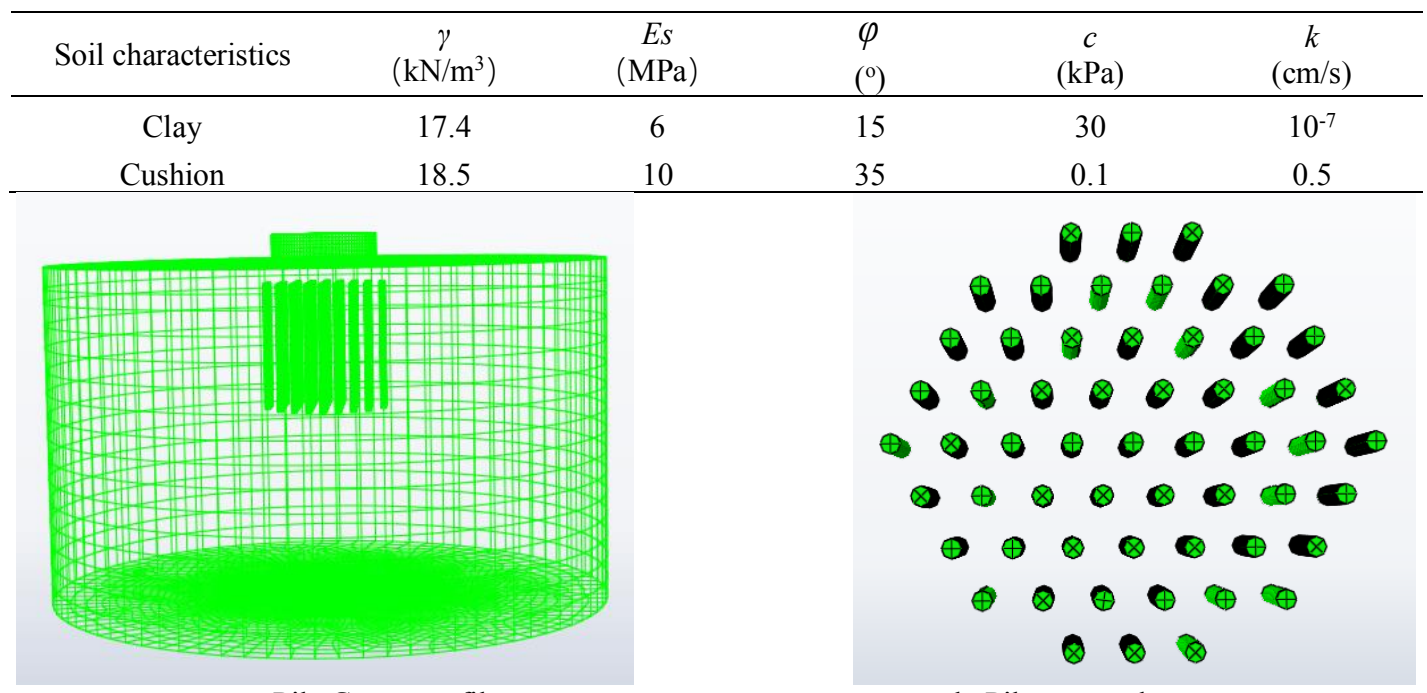

a. Pile Group profile

Figure 1. Model meshing

b. Pile group plane

and vertical displacement is free in the surrounding border;

\subsection{Calculation process}

Selecting Element: The adopted finite element software is ABAQUS. The reduced-integration 3D solid element with eight-node (C3D8R) is suitable for contact analysis and large strain analysis, and is selected for the soil, pile and upper foundation in this simulation model.

Constitutive model: When selecting constitutive modalities, the precision and the accuracy of the model should be focused on. In the model, the elastic-perfectly plastic constitutive model (Mohr-Coulomb model) is used for the soil and the linear elastic model is used for foundation and piles.

Contact interface: The contact pairs of the discrete face-to-face contact is used. The outer surface of the pile serves as the main control surface and the soil surface in contact with the pile serves as the subordinate surface, the hard contact is adopted for the normal model of the interface, the longitudinal friction between faces is expressed by a coefficient of friction- $\mu$.

Loading method: The incremental iteration method is adopted, iteration is carried out with automatically the loading step.

Boundary conditions: horizontal displacement is fixed
The horizontal and vertical displacement are fixed in the bottom border.

Basic assumptions: Soil is homogeneous, isotropic single continuum in the formation; Pile embedding does not affect the soil compressive modulus and Poisson's ratio and other physical and mechanical parameters; Pile and foundation as a linear elastomer, conform to the generalized Hook's law; Pile, soil, cushion are isotropic.

The initial stress state due to gravity in the pile and the soil don't be considered.

\section{Results and analysis}

Because of the stress balance layer, the additional load is transferred to the pile and the soil between the piles, and all the way to the deep. According to the calculation results, the soil stress distribution of piles and soil can be obtained. The stress of soil around pile is at the position between the central pile and its adjacent piles.

\subsection{Stress distribution of pile body}

The stress distributions of piles body under different pile lengths and different pile spacings with the loading of 
$200 \mathrm{kPa}$ are shown in Figure 2. Stress of piles increase with pile spacing and pile length, the stress of a pile increases

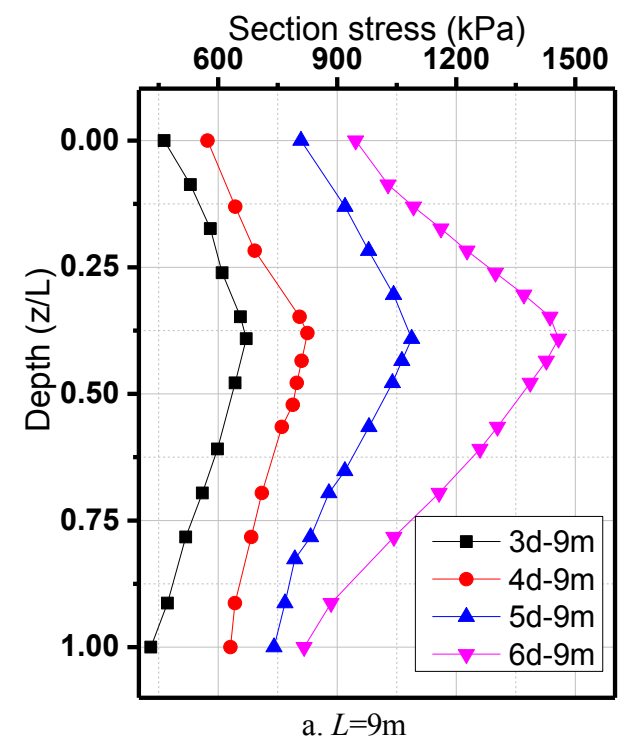

The pile length is $9 \mathrm{~m}$, the maximum position is about $3.6 \mathrm{~m}$ below the top of the pile, that is slightly larger than $L / 3$; The pile length is $12 \mathrm{~m}$, the maximum position is about $4 \mathrm{~m}($ i.e. $L / 3$ ) below the top of the pile; The pile length is $15 \mathrm{~m}$, the maximum position is about $4.4 \mathrm{~m} \sim 4.8 \mathrm{~m}($ i.e. $L / 4 \sim L / 3$ ) below the top of the pile; The

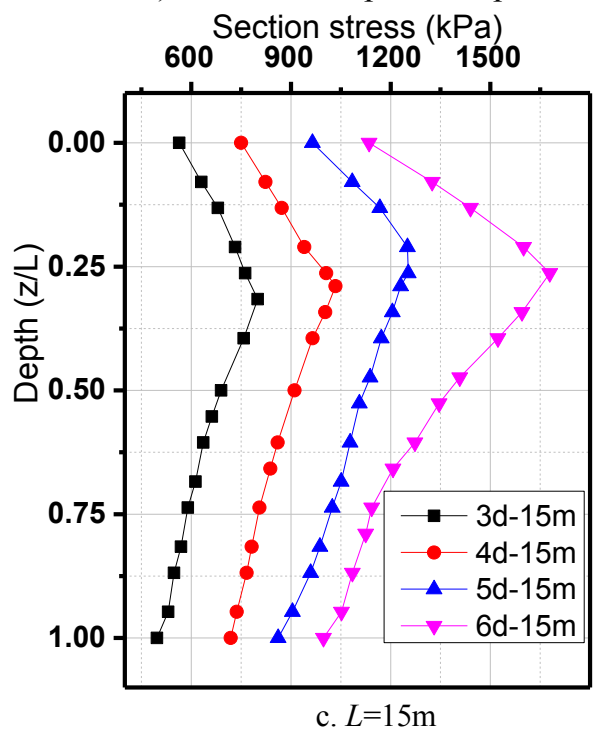

and then decreases along the pile body.

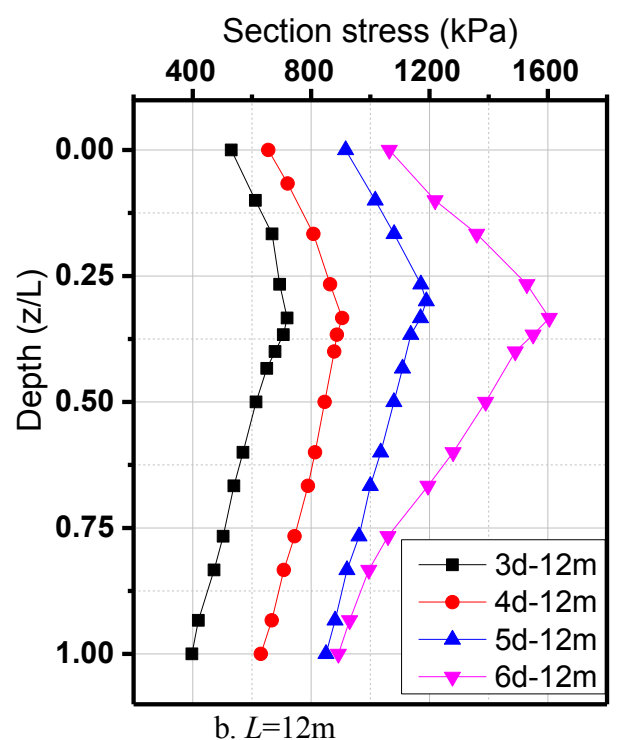

pile length is $18 \mathrm{~m}$, the maximum position is about $4.8 \mathrm{~m} \sim 5.2 \mathrm{~m}($ i.e. $L / 4 \sim L / 3)$ below the top of the pile; The pile length is $21 \mathrm{~m}$, the maximum position is about $5.2 \mathrm{~m}($ i.e. $L / 4$ ) below the top of the pile. These are consistent with the results of many scholars.

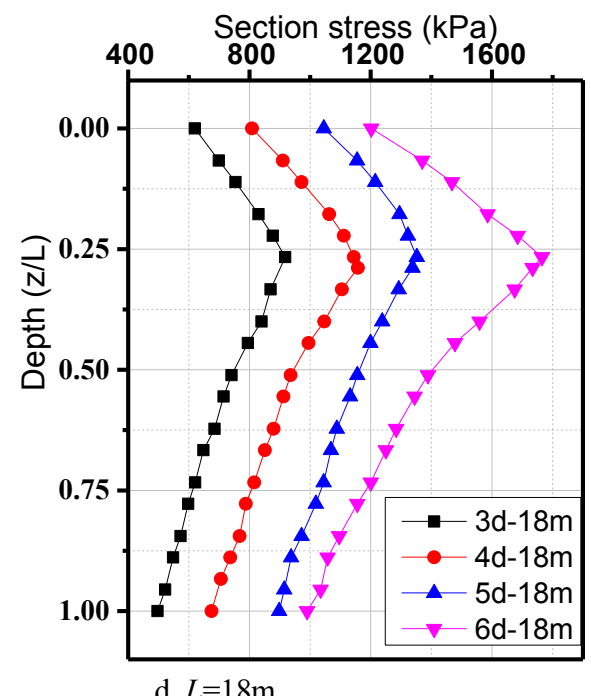




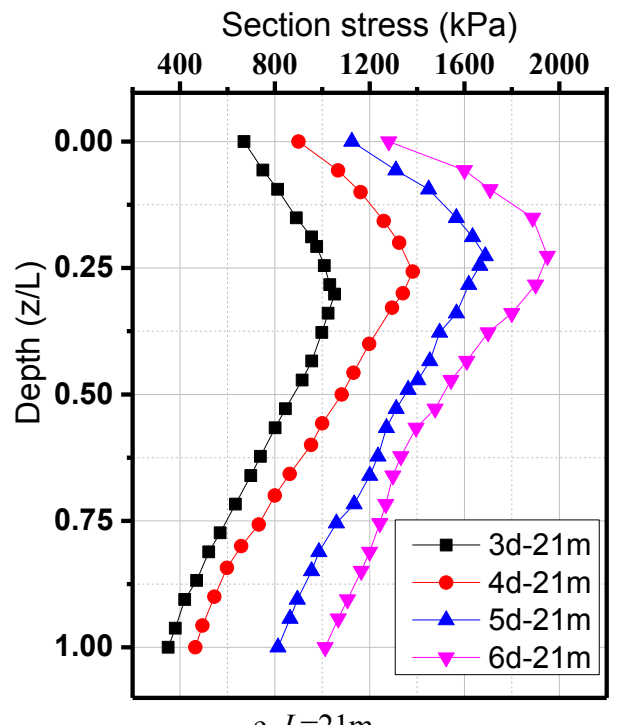

Note: in F2, Ordinate $\mathrm{z} / \mathrm{L}$ is the ratio of any depth to pile length.

Figure 2. Curve of stress of pile section with different pile space and pile length

The stress at the pile top and maximum stress of pile body are shown as Table 3.

Table 3. Stress at the pile top, maximum stress of pile body

\begin{tabular}{ccccccccc}
\hline $\begin{array}{c}\text { Pile length } \\
(\mathrm{m})\end{array}$ & $\begin{array}{c}\text { SPT } \\
(\mathrm{kPa})\end{array}$ & $\begin{array}{c}\text { MSPB } \\
(\mathrm{kPa})\end{array}$ & $\begin{array}{c}\text { SPT } \\
(\mathrm{kPa})\end{array}$ & $\begin{array}{c}\text { MSPB } \\
(\mathrm{kPa})\end{array}$ & $\begin{array}{c}\text { SPT } \\
(\mathrm{kPa})\end{array}$ & $\begin{array}{c}\text { MSPB } \\
(\mathrm{kPa})\end{array}$ & $\begin{array}{c}\text { SPT } \\
(\mathrm{kPa})\end{array}$ & $\begin{array}{c}\text { MSPB } \\
(\mathrm{kPa})\end{array}$ \\
\hline 21 & 670 & 1052.3 & 900 & 1382 & 1125 & 1688 & 1280.4 & 1950 \\
18 & 619.8 & 918.2 & 808.5 & 1158 & 1045.1 & 1338 & 1202 & 1780 \\
15 & 563.8 & 800.7 & 750 & 1034 & 964.5 & 1253 & 1135 & 1679 \\
12 & 530 & 719.3 & 655 & 905.2 & 917 & 1189.2 & 1064.2 & 1605 \\
9 & 463 & 670.6 & 573.1 & 798 & 808.3 & 1087.4 & 946.2 & 1298.8 \\
\hline
\end{tabular}

Note: 1 . SPT- Stress at the pile top, MSPB- maximum stress of pile body.

\section{2. $S a$ - Pile spacing.}

From the table 3, Under the same pile length, the differences of the maximum stress of pile body from the stress at the pile top increase with the pile spacing increasing; Under the same pile spacing, the differences of the maximum stress of pile body from the stress at the pile top increase with the pile length increasing.

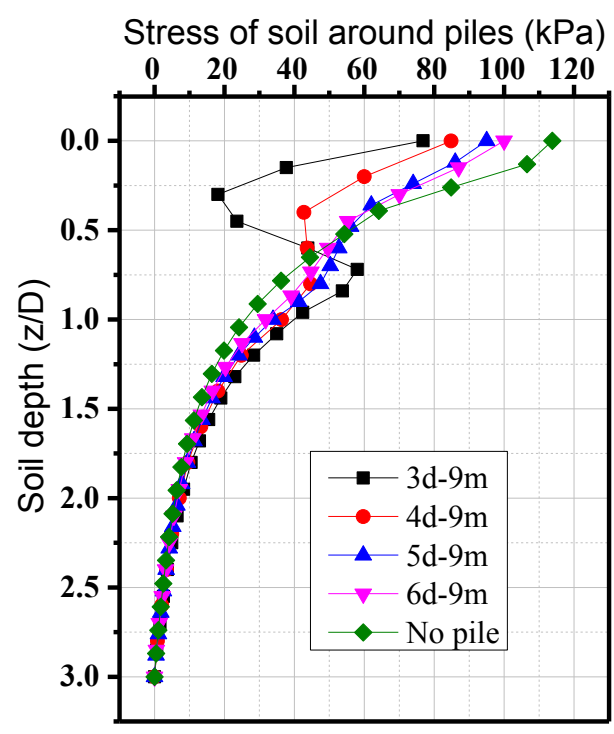

a. $L=9 \mathrm{~m}$

\subsection{Stress distribution of soil}

Figure 3 is the curves of the additional stress of soil around the piles near the center with depth and the additional stress of nature foundation.

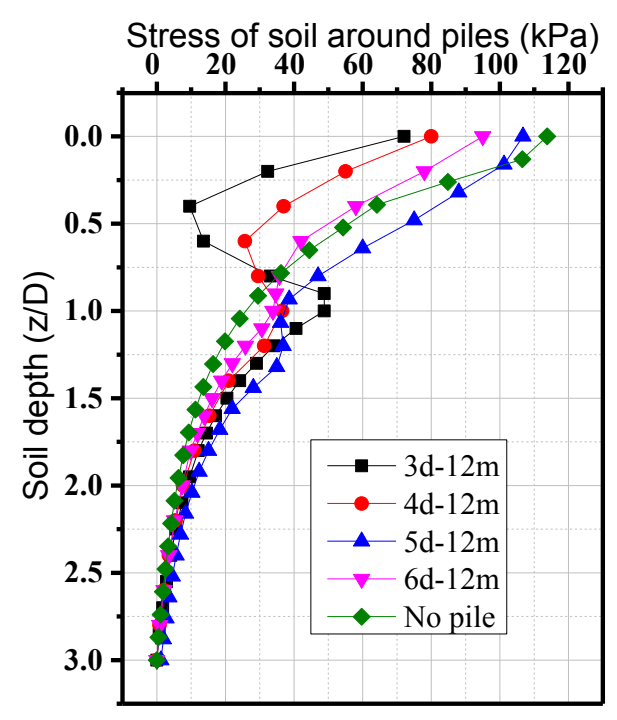

b. $L=12 \mathrm{~m}$ 


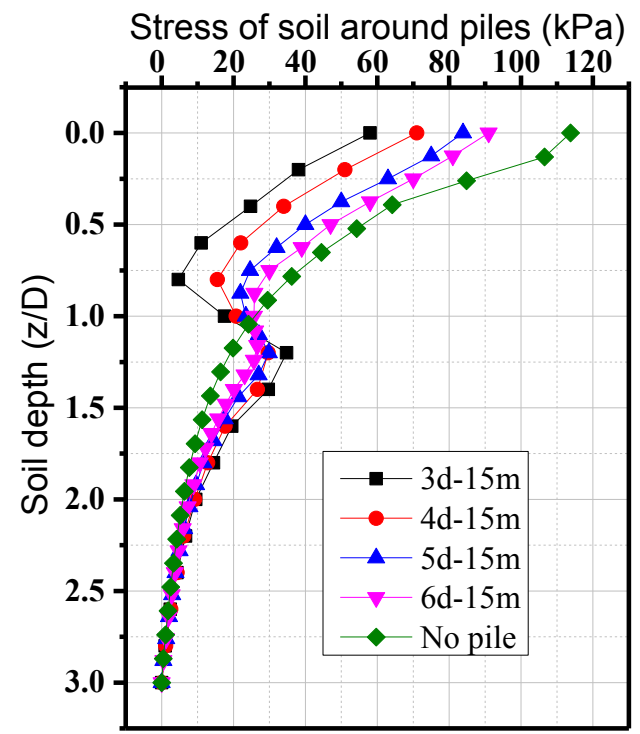

c. $L=15 \mathrm{~m}$

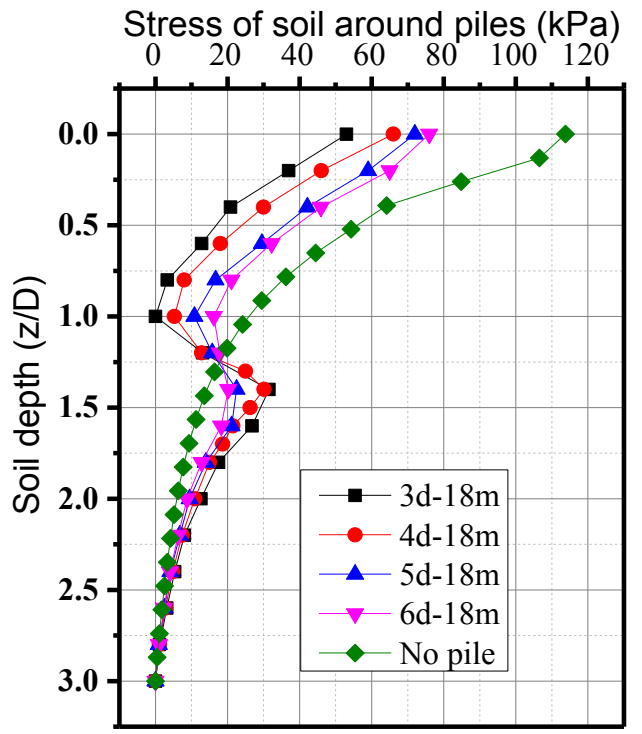

d. $L=18 \mathrm{~m}$

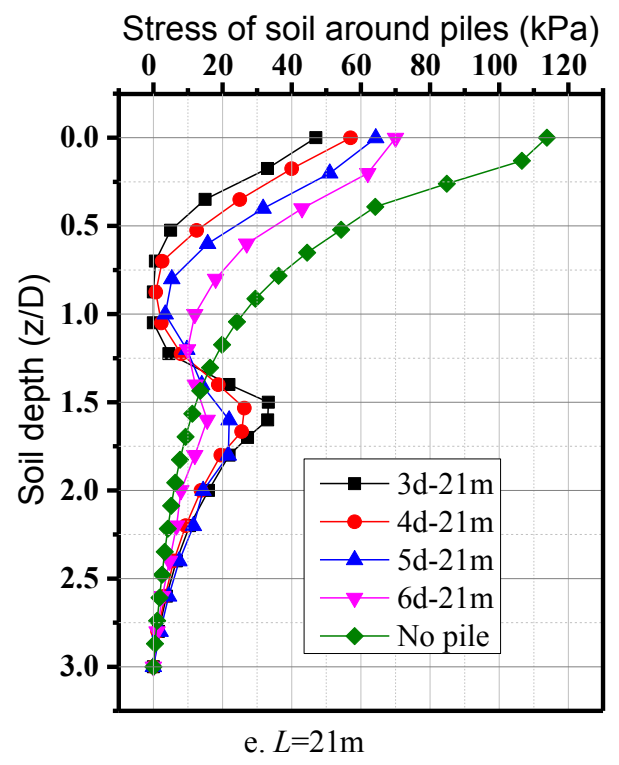

Note: in FIG.3, "D" is diameter of foundation.

Figure 3. Curve of the stress of soil with different pile space and pile length

In this Figure, From the bottom of foundation to the depth of $6 \mathrm{~m}$ additional stress attenuation slow in nature foundation. Pile spacings are $3 d$ and $4 d$, the stress of soil around pile firstly decreases and then increases with the increasing depth in the range of pile length, the minimum value appears at the position where is about $3 \mathrm{~m}$ above pile tip. When pile lengths are respectively $9 \mathrm{~m}, 12 \mathrm{~m}, 15 \mathrm{~m}$, $18 \mathrm{~m}$ and $21 \mathrm{~m}, \mathrm{z} / \mathrm{D}$ are respectively $0.4,0.6,0.8,1.0$ and 1.2. Then, the additional stress of the soil increases with the increasing depth, until it reaches maximum value at the position where is about $3 \mathrm{~m}$ below the pile tip. When pile lengths are respectively $9 \mathrm{~m}, 12 \mathrm{~m}, 15 \mathrm{~m}, 18 \mathrm{~m}$ and $21 \mathrm{~m}$, $\mathrm{z} / \mathrm{D}$ are respectively0.8, 1.0, 1.2, 1.4 and 1.6. That means pile tip affects the additional stress of soil of the plane not only below pile tip but also above pile tip. After the additional stress reaches the maximum value, it decreases with increasing depth until it disappears. The pile spacing is $5 d$, the pile length is less than $18 \mathrm{~m}$, the stress of soil around the piles decreases gradually along the pile length, the more slowly at the closer the pile end, at $1.5 \mathrm{~m}$ below the pile tip the stress goes down faster; When the pile length increases to $21 \mathrm{~m}$, the stress of soil around the piles reach to the minimum value, then slightly increased along the depth to $3 \mathrm{~m}(\mathrm{z} / \mathrm{D}$ is 1.6$)$ below the pile end where stress goes down faster. This phenomenon shows that when the pile spacing is $5 d$, the soil around the piles is still affected by the pile tip, but the effect is weaker relative to the pile spacing of $3 d$ and $4 d$. When the pile spacing is $6 d$, the additional stress of the soil is less affected by the pile end.

Additional stress can be ignored when it is less than 0.1 times the weight of soil, the influence depth of additional stress is $21.5 \mathrm{~m}$ under the load of $120 \mathrm{kPa}$ in the foundation without pile. The depth of influence of additional load in the foundation with pile is shown in Table 4. 
Table 4. Influence depth of additional load.

\begin{tabular}{ccccc}
\hline $\begin{array}{c}\text { Pile length } \\
(\mathrm{m})\end{array}$ & $3 d$ & \multicolumn{3}{c}{ Influence depth $(\mathrm{m})$} \\
\hline 9 & 12.6 & $4 d$ & $5 d$ & $6 d$ \\
12 & 10.5 & 12.1 & 12.2 & 11.6 \\
15 & 8.5 & 10.35 & 9.8 & 9.5 \\
18 & 7.6 & 8.2 & 7.7 & 7.2 \\
21 & 6.2 & 6.5 & 6.7 & 4.8 \\
\hline
\end{tabular}

Note: Impact depth is calculated from the pile tip.

From the table we can see that the total depth of influence increases with the increasing pile length, but the depth of influence on the soil below the pile tip decreases. Because he length of the pile is longer, the frictional resistance is larger, loading is transferred from the pile body to the soil around the pile.

To sum up the above analysis, we can see that the pile spacing is smaller, the additional load in the piles is greater, which is transmitted to the pile tip is greater and the influence of stress distribution of the soil around pile is greater. When the pile length is $9 \mathrm{~m}$, the influence depth of additional load almost equal to the natural foundation. The pile length is longer, the influence depth of additional load is more deeper, but the influence of additional stress on the soil beneath the pile tip becomes smaller with the increase of pile length.

The additional stress of soil due to the presence of pile is smaller than that of no pile. The pile spacing is smaller, the difference the distribution of additional stress is the more obvious than of non-pile.

\section{3 pile-soil stress ratio}

Leung's systematic analysis ${ }^{[12]}$ proved that pile length plays an important role in the bearing of composite foundation, which affects not only the settlement but also the load sharing ratio between pile and soil. Figure 4 is relationship between pile - soil stress ratio and pile length with different pile spacing. From Figure 4, pile-soil stress ratio increases with the increase of pile spacing and it substantially linearly increases with the increasing length. This shows that in the range of effective pile length, the longer the pile, the greater the friction resistance of the pile, the pile bears more load and the corresponding axial stress of pile top increases. Pile-soil stress ratios are shown in Table 5.

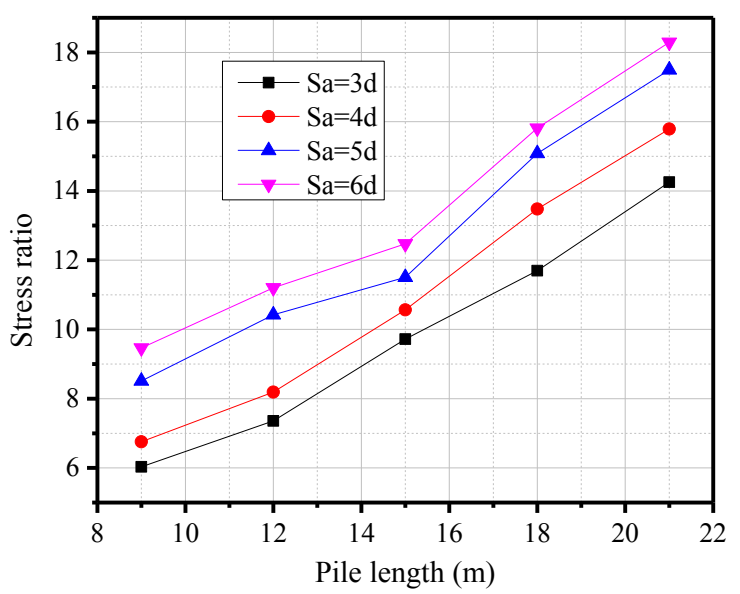

Figure 4. Curve of the stress ratio -pile length

Table 5. Pile-soil stress ratios

\begin{tabular}{ccccc}
\hline Pile length $(\mathrm{m})$ & $S a=3 d$ & $S a=4 d$ & $S a=5 d$ & $S a=6 d$ \\
\hline 21 & 14.3 & 15.8 & 17.5 & 18.3 \\
18 & 11.7 & 13.5 & 15.1 & 15.8 \\
15 & 9.7 & 10.6 & 11.5 & 12.5 \\
12 & 7.4 & 8.2 & 10.4 & 11.2 \\
9 & 6.0 & 6.8 & 8.5 & 9.5 \\
\hline
\end{tabular}

From the table, the pile-soil stress ratio is relatively small although the stiffness of the pile is much larger than that of the soil, the maximum value does not exceed 20 . This shows that most of the load transfer to the soil around the piles because soil is soft and deep so that pile can not reach bedrock.

\section{Conclusions}

According to the analysis of numerical simulation results of thick soft soil composite foundation with rigid pile, we can get following conclusions:

a. Transferring rules of additional load: When the pile spacing is less than or equal to $4 d$, the additional stress of soil around piles decreases with the increasing depth from the pile top to the position of $3 \mathrm{~m}$ above the pile tip where the value of the additional stress of soil around piles is minimum. After that, the additional stress started to increase with the increasing depth reaching the maximum value until $3 \mathrm{~m}$ below the pile tip. Then, additional stress begins to decrease until it disappears with the increasing depth. When the pile spacing is $5 d$, the above characteristics are not obvious. When the pile spacing is $6 d$, the soil around the piles is not affected by the pile-end, which is similar to the rule that the stress changes with the depth when there is no pile.

b. The pile stress firstly increases and then decreases along the pile length, and the position at where maximum value appears is between $L / 4$ and $L / 3$. 
c. The additional stress increases with the increasing pile length and the influence depth below the pile tip decreases; The influence of additional stress decreases with increasing pile spacing

d. The pile-soil stress ratio firstly increases and then decreases with the increasing pile length and pile spacing.

\section{REFERENCES}

1. Wang Bing, Yang Weimin, Li Zhanqiang etc. (2008). "Test study on influence of cushion on loading behavior of composite foundations." Rock and Soil Mechanics, Vol. 29 (2):403-408.

2. Xie, Y., Leung C. F., Chow, Y. K. (2012). "Centrifuge modelling of spudcan-pile interaction in soft clay". Ge 'otechnique, Vol. 62(9): 799-810.

3. Chi Yuejun, Song Erxiang, Chen Zhaoyuan (2003). "Analysis of bearing performance of rigid pile composite foundation under vertical loads." Engineering Mechanics, Vol. 20 (4): 9-14.

4. Xue Xinhua, Wei Yongxing, Yang Xingguo etc. (2012). "Indoor model test study on CFG pile composite foundation." China Railway Science, Vol. 33 (2): 7-12.

5. Miao Linchang, Wang Fei, Lv Weihua (2014). "Calculation method of stress concentration ratio of pile to soil of rigid pile composite foundation." Chinese Journal of Underground Space and Engineering, Vol. 10(06): 1270-1275.

6. Zhao Minghua, Chen Qing, Zhang Ling (2009). "Calculation of pile-soil stress ratio of rigid pile composite foundation with consideration of piles upward puncture deformation." Journal of Highway and Transportation Research and Development, Vol. 26(10): 38-43.

7. Zhu Xiaojun, Zhao Xueliang, Gong Weiming etc (2014). "Study on failure mechanism of cushion in rigid pile composite foundation." China Journal of Highway and Transport, Vol. 27(05): 105-111.

8. Li Li, Bao Peng, Zhao Jie (2010). "Model experimental study on composite foundation with rigid piles." Building Structure, Vol. 40 (01): 29, 69-70.

9. Zheng Gang, Liu Shuangju, Wu Zhichao (2006). "Study on behavior of rigid pile composite ground with different cushion thicknesses." Rock and Soil Mechanics, Vol. 27(08): 1357-1360.

10. Yang Dejian, Wang Tiecheng, Liu Rui (2011). "Study on settlement character and influence factors of rigid pile composite-foundation." Architecture Technology, Vol. 42(03): 235-238.

11. Yang Dejian, Wang Tiecheng (2010). "Research on settlement mechanism and influence factors of rigid pile composite-foundation." Engineering Mechanics, Vol. 27 (S1): 150-153.

12. Sun Xunhai, Xu Lihe, Li Yanxia etc. (2010). "Effect of foundation rigidity on pile-soil load share ratio of rigid pile composite foundation." Chinese Journal of
Geotechnical Engineering. Vol. 32(06): 850-855.

13. Leung, Y. F., Klar A., Soga, K. (2010). “Theoretical Study on Pile Length Optimization of Pile Groups and Piled Rafts." Journal of Geotechnical \& Geoenvironmental Engineering, Vol. 136(2): 319-330. 